\title{
DEGENERATIONS OF THE DOG RETINA* \\ VI. CENTRAL PROGRESSIVE ATROPHY WITH PIGMENT EPITHELIAL DYSTROPHY
}

BY

\author{
H. B. PARRY $\dagger$ \\ Animal Health Trust, Kennett, Newmarket, Suffolk
}

THIS syndrome of central progressive atrophy of the retina in which central vision is lost in middle age while peripheral vision is retained until old age is unlike the generalized degenerations of the dog retina described in the preceding papers of this series, in two principal particulars: the distribution of the degeneration and the occurrence in the fundus of pigment foci which may be seen with the ophthalmoscope.

The syndrome was first recognized clinically when small foci of irregular pigmentation were observed in the tapetal fundus of dogs with a history of very gradual bilateral impairment of day and night vision coming on in middle or late life. The impairment of vision was due to the development of a central scotoma; the day and night vision of the peripheral fundus remained unimpaired.

The electroretinogram was normal in the early stages of the disease, but in the later stages first the negative wave could not be detected and finally the $b$-wave was lost.

In histological preparations the central retina was found to be degenerate, the pigment epithelium dystrophic, and the choroid somewhat thinned.

\section{Material and Methods}

The methods and terminology have been described previously (Parry, $1953 \mathrm{a}, \mathrm{b}, \mathrm{c}$ ). Fifteen cases have been under observation, details of which are given in the Table (overleaf).

Ten were examined at autopsy. Electroretinography was carried out in four cases by the team (Parry, Tansley, and Thomson, 1953). Of the fifteen dogs, eleven were referred to us by their owners on account of defective vision, nine being trained gundogs and two house pets. The remaining four (Cases 1-4) were animals being kept in our research kennels in connection with our studies of hereditary generalized retinal atrophy (Parry, 1953b).

\section{Results}

(1) Changes in the Eye.-The clinical and pathological data in these cases showed a striking sequence of increasing severity, and it is convenient to describe them as the three stages of a single syndrome, affecting both eyes symmetrically, each stage being sub-divided into an early phase $(a)$ and a late phase $(b)$.

Stage 1.-Day and night vision and the electroretinogram were normal, but small foci of hypertrophic pigment epithelial cells appeared, which in Stage $1 a$ could only be detected in microscopic preparations. During Stage $1 b$ the atrophy of the retina commenced and

* Received for publication October 10, 1953.

+ Present address: Nuffield Institute for Medical Research, Oxford. 
TABLE

DETAILS OF DOGS AFFECTED WITH CENTRAL RETINAL

\begin{tabular}{|c|c|c|c|c|c|c|}
\hline \multirow{2}{*}{$\begin{array}{l}\text { Case } \\
\text { No. }\end{array}$} & \multirow{2}{*}{ Breed } & \multirow{2}{*}{ Sex } & \multirow{2}{*}{$\begin{array}{l}\text { Age when } \\
\text { Disease } \\
\text { First Noted } \\
\text { (yrs) }\end{array}$} & \multicolumn{2}{|c|}{ Clinical Examination } & \multirow{2}{*}{ Electroretinogram } \\
\hline & & & & $\begin{array}{l}\text { Age } \\
\text { (yrs) }\end{array}$ & $\begin{array}{l}\text { Stage of } \\
\text { Disease }\end{array}$ & \\
\hline 1 & Border Collie (DO 49) & $\mathbf{M}$ & - & $1 \frac{1}{2}$ & 0 & - \\
\hline 2 & Border Collie (DO 48) & $\mathrm{F}$ & - & 2 & 0 & - \\
\hline 3 & Red Irish Setter (DH 18) & $\mathrm{F}$ & $1 \frac{1}{2}$ & $1 \frac{1}{2}$ & $1 b$ & $\begin{array}{l}\text { Normal then } \\
\text { slow loss of } \\
\text { negative wave }\end{array}$ \\
\hline 4 & Border Collie (DO 51) & $\mathbf{M}$ & 3 & 3 & $1 b$ & Normal \\
\hline 5 & Black Labrador & $F$ & 2 & 3 & $2 a$ & - \\
\hline 6 & Black Labrador & $\mathbf{M}$ & 1 & $1 \frac{1}{4}$ & $2 a$ & - \\
\hline 7 & Yellow Labrador & $\mathbf{M}$ & 3 & 4 & $2 a$ & - \\
\hline 8 & Springer Spaniel & $\mathbf{F}$ & $2 \frac{1}{2}$ & 3 & $2 b$ & - \\
\hline 9 & Black Labrador & $\mathrm{F}$ & $2 \frac{1}{4}$ & 3 & $2 b$ & - \\
\hline 10 & Golden Retriever & $\mathrm{F}$ & 5 & 9 & $2 b$ & $\begin{array}{c}b \text {-wave and neg- } \\
\text { ative wave of } \\
\text { low voltage }\end{array}$ \\
\hline 11 & Black Labrador & $\mathbf{M}$ & 5 & 6 & $2 b$ & - \\
\hline 12 & Black Labrador (DO 76) & $\mathbf{M}$ & $1 \frac{1}{2}$ & 2 & $2 b$ & $\begin{array}{l}b \text {-wave and small } \\
\text { wave both } \\
\text { gradually lost }\end{array}$ \\
\hline 13 & Black Labrador & $\mathbf{M}$ & 7 & 8 & $3 b$ & - \\
\hline 14 & Collie $\times$ Irish Water Spaniel & $\mathbf{M}$ & 8 & 12 & $3 b$ & - \\
\hline 15 & Black Labrador & $\mathbf{M}$ & 2 & 8 & $2 b$ & - \\
\hline
\end{tabular}

foci of hypertrophic pigment epithelial cells were visible on ophthalmoscopic examination.

Stage 2.-The dog showed signs of a central scotoma with good peripheral vision. The electroretinogram could still be detected but the negative wave was of low voltage and was gradually lost, followed by loss of the $b$-wave. The pigment foci remained. The central retina became completely sclerosed while the peripheral retina remained normal.

Stage 3.- Peripheral vision was lost. An electroretinogram was not detectable. The peripheral fundus underwent atrophy (Stage $3 a$ ) which progressed to complete sclerosis (Stage $3 b$ ).

The terms atrophy and sclerosis are used to denote the two stages: the first in which the layer organization of the retina persisted, and the second in which it was lost in an unorganized glial matrix. 
ATROPHY WITH PIGMENT CELL DYSTROPHY

\begin{tabular}{|c|c|c|c|c|c|}
\hline \multicolumn{3}{|c|}{ Pathological Examination } & \multirow{2}{*}{$\begin{array}{l}\text { Stage } \\
\text { of } \\
\text { Disease }\end{array}$} & \multirow[b]{2}{*}{ Pertinent Medical History } & \multirow{2}{*}{$\begin{array}{l}\text { Disease } \\
\text { Type }\end{array}$} \\
\hline $\begin{array}{l}\text { Age } \\
\text { (yrs) }\end{array}$ & $\begin{array}{l}\text { Central } \\
\text { Retina* }\end{array}$ & $\begin{array}{l}\text { Peripheral } \\
\text { Retina* }^{*}\end{array}$ & & & \\
\hline $1 \frac{1}{2}$ & $\begin{array}{l}\text { PE hypertrophy } \\
\text { Atrophy }\end{array}$ & Normal & $1 a$ & Virus hepatitis at $1 \frac{1}{2}$ yrs & A \\
\hline 2 & $\begin{array}{l}\text { PE hypertrophy } \\
\text { Atrophy }\end{array}$ & Normal & $1 a$ & Virus hepatitis at $1 \frac{1}{2}$ yrs & $\mathbf{A}$ \\
\hline 2 & Atrophy + & Normal & $1 b$ & $\begin{array}{l}\text { Para-distemper at } 3 \text { mths; } \\
\text { inapparent virus hepa- } \\
\text { titis at } 1 \text { yr }\end{array}$ & B \\
\hline 3 & Sclerosis + & Normal & $2 a$ & Virus hepatitis at $1 \frac{1}{2}$ yrs & $\mathbf{A}$ \\
\hline- & - & - & $2 a$ & - & $\mathbf{A}$ \\
\hline- & - & - & - & None & $\bar{A}$ \\
\hline 4 & Sclerosis + & Normal & $2 b$ & Jaundice at $1 \mathrm{yr}$ & $\mathbf{A}$ \\
\hline- & - & - & - & $\begin{array}{l}\text { Severe para-distemper at } \\
2 \text { yrs }\end{array}$ & $\mathbf{B}$ \\
\hline- & - & - & - & None & A \\
\hline 9 & $\begin{array}{c}\text { Sclerosis }++ \\
.\end{array}$ & Normal & $2 b$ & None $\bullet$ & A \\
\hline 8 & Sclerosis + & Atrophy ++ & $2 b$ & None & $\mathbf{A}$ \\
\hline 3 & Sclerosis + & Atrophy + & $3 a$ & None & $\bar{A}$ \\
\hline 8 & Sclerosis ++ & Sclerosis + & $3 b$ & $\begin{array}{l}\text { Convulsions and mental } \\
\text { confusion at } 10 \mathrm{mths}\end{array}$ & A \\
\hline 12 & Sclerosis ++ & Sclerosis + & $3 b$ & None & B \\
\hline- & - & - & - & None & A \\
\hline
\end{tabular}

*moderate + severe ++

\section{Stage 1}

Clinical Data: Four cases were observed in this stage. The earliest sign of the disease will only be detected during frequent routine ophthalmoscopic examinations. The first sign of the disease, before any visual defect was noted, was the appearance of foci of brown pigment over the tapetal fundus. These foci were irregular in outline and $0.05-0.1 \mathrm{~mm}$. in diameter. They appeared $0.5-2.0 \mathrm{~mm}$. apart and were not related to the retinal blood vessels. The texture of the fundus, the stellulae of Winslow, and the retinal blood vessels were normal, although the granularity of the fundus was somewhat reduced; the papilla was rather pale but otherwise normal. The average pupil size tended to be rather larger than normal, i.e. $6-8 / 14 \mathrm{~mm}$. Day and night vision were normal. The size and tension of the eyeballs were normal, as were the other ocular structures. 
Electroretinography.-The electroretinogram was normal in one dog (Case 4), but in another animal, Case 3, in which it was recorded six times between the ages of 1 and 2 years while the pigment foci were developing, there was a gradual reduction of the slow negative component of the electroretinogram in both eyes, although there was no detectable defect of day or night vision.

Morbid Anatomy.-Three cases were examined at autopsy; no macroscopic abnormality of the optic nerves or brain was found.

Histology.-In the earliest phase, (Stage $1 a$; Cases 1 and 2) the retina was virtually normal, the only lesion being a moderate thickening of the cells of the pigment epithelium to about 7-8 $\mu$ in small foci up to $20 \mu$ in diameter (Case 1). This hypertrophy spread and involved the epithelium over most of the tapetal fundus in Case 2, which was 6 months older at death than her litter-brother Case 1; at the same time a definite increase of glial fibres just beneath the internal limiting membrane was apparent and the ganglion cells were rather less numerous than normal near the papilla. The remaining layers of the retina appeared normal. The choroid was

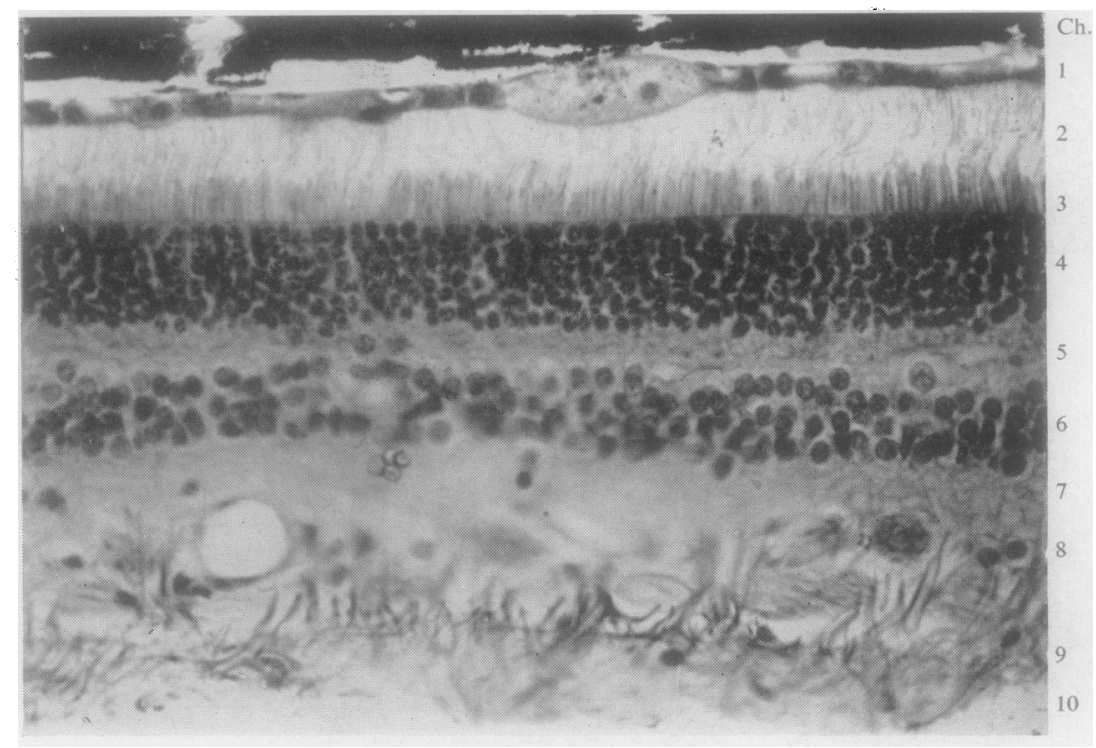

FIG. 1.-Section through retina of 2-yr-old Red Irish Setter dog (Case 3) at Stage $1 b$ of central degeneration, showing ventral edge of tapetal fundus near papilla. Note giant cell in pigment epithelium. There is gliosis of the optic nerve fibre layer. The large retinal blood vessel, the chorio-capillaris, and the trans-tapetal capillary on the left are all normal. Intravital fixation with Kolmer's cold-blooded fixative. Mallory's phosphotungstic acid haematoxylin. $\times 330$.

The following code for labelling the retinal structures applies to all the figures:

$\begin{array}{ll}\text { Sc. Sclera } & \text { 3. External limiting membrane } \\ \text { Ch. Choroid } & \text { 4. Outer nuclear layer } \\ \text { Tap. Tapetum } & \text { 5. Outer fibre layer } \\ \text { C.C. Chorio-capillaris } & \text { 6. Inner nuclear layer } \\ \text { Ret. Retina } & \text { 7. Inner fibre layer } \\ \text { 1. Pigment epithelium } & \text { 8. Ganglion cell layer } \\ \text { 2. Rod and cone layer } & \text { 9. Optic nervi fibres }\end{array}$

10. Internal limiting membrane 
slightly less thick than usual and its blood vessels less prominent, but they were otherwise normal.

In the late phase (Stage $1 b$, Case 3 ) signs of an early atrophy of the retina occurred symmetrically over the whole of the tapetal fundus and the immediately adjacent dorsal non-tapetal fundus. The peripheral fundus remained normal apart from some increase of glial fibres, but in the central fundus the changes involved the pigment epithelium, the rods and cones and their nuclei, and the ganglion cells and nerve fibre layer. The inner nuclear and adjoining fibre layers were but little affected. The abnormalities in the pigment epithelium ranged from an occasional large hypertrophic cell $10 \mu$ long and $15 \mu$ wide (Fig. 1), through bizarre-shaped pigment cells heavily loaded with light-brown refractile pigment granules (Fig. 2) staining a deep blue with the azan technique, to multicellular " nests" of pigment cells up to $100 \mu$ long and $40-50 \mu$ wide (Fig. 3, overleaf), the cells of which were less heavily loaded with similar pigment granules. The rods and cones were reduced very considerably immediately adjacent to the enlarged pigment cells and the "nests" (Figs 1, 2, and 3), but elsewhere they were little affected although the outer limbs appeared less robust than usual. Over the mid-tapetal fundus there was a general reduction in the thickness of the rods and cones and of the outer nuclear layer due to loss of rod nuclei (Fig. 2), and in some foci adjacent to the giant pigment cell. " nests" the rods and their nuclei were completely absent. The ganglion cells were somewhat less numerous than normal, and most of the remaining giant ganglion cells showed evidence of degenerative changes in the loss of definition of the cell components. The optic nerve fibres were reduced, particularly near the papilla, and the papilla itself was vacuolated and shrunken, while the optic nerve central to the lamina cribrosa showed less marked degenerative changes. The

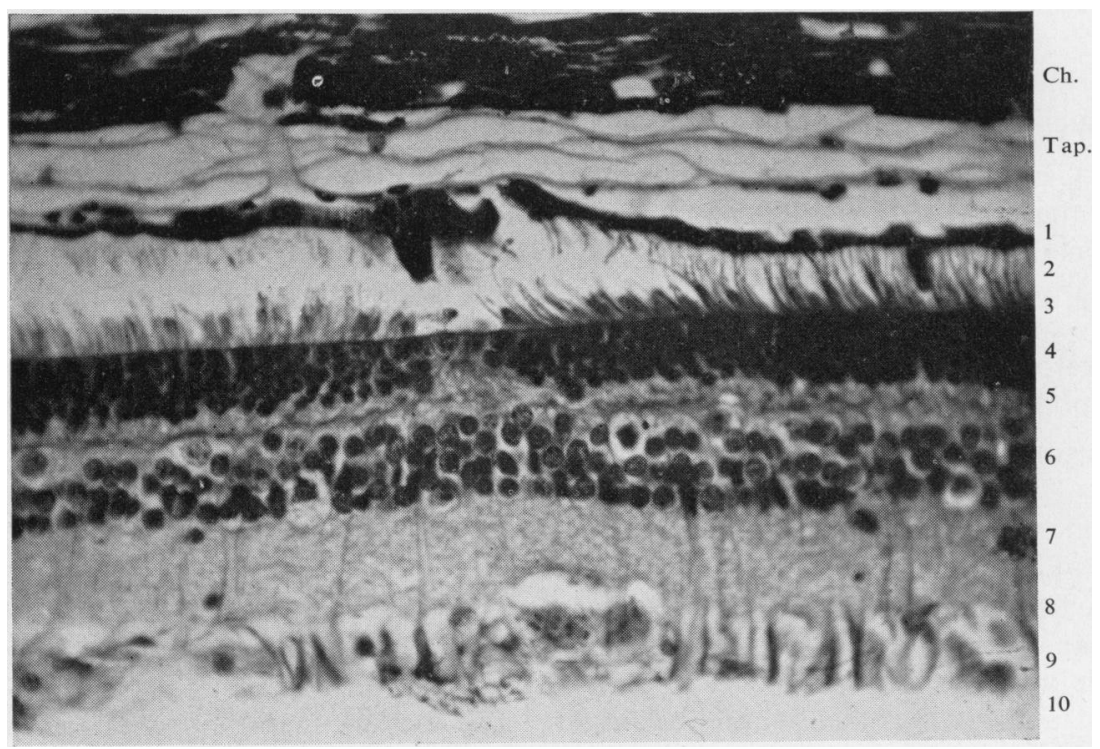

FIG. 2.-Same preparation as Fig. 1, mid-tapetal fundus. Note occasional bizarreshaped pigment epithelial cells, and adjacent disappearance of rods and cones and outer nuclear layer. The remainder of the outer nuclear layer is about half the normal thickness. The inner nuclear and adjoining fibre layers are normal. $\times 330$. 


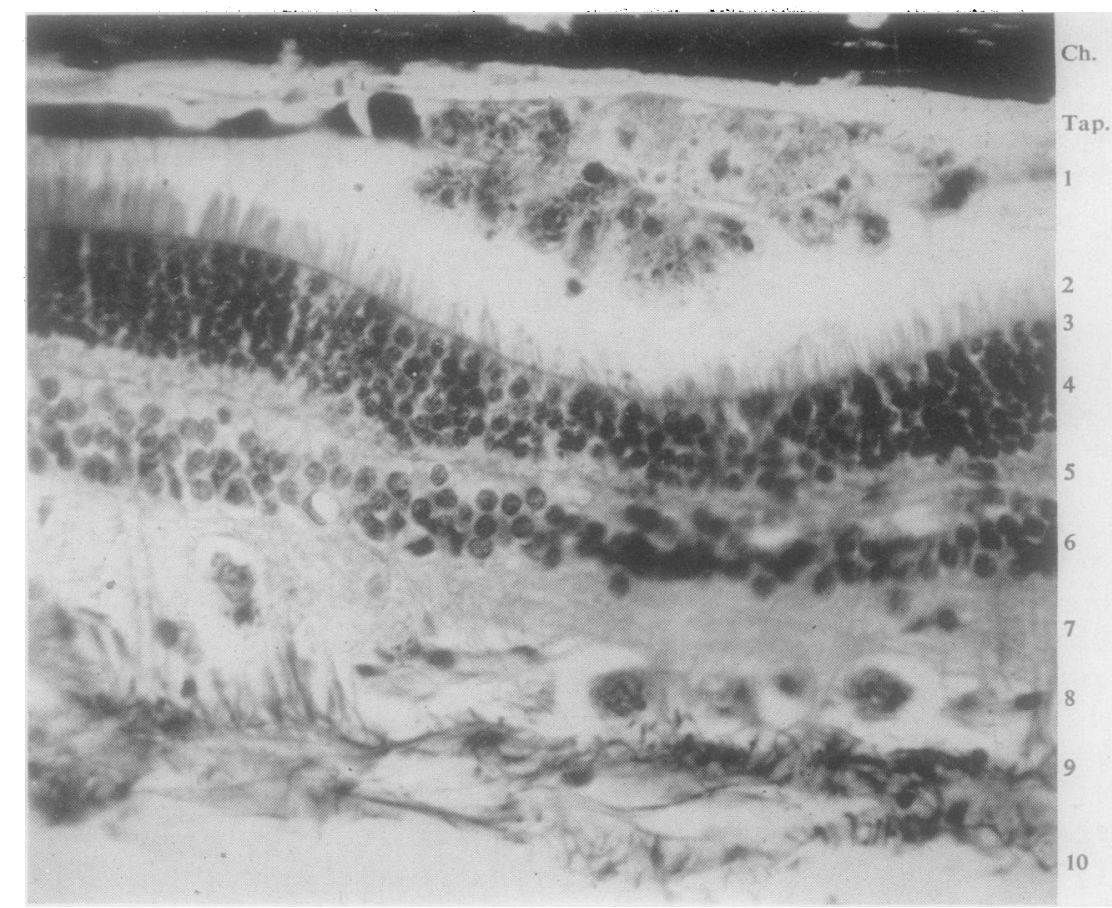

FIG. 3.-Same preparation as Figs 1 and 2, mid-tapetal fundus near papilla. Note hypertrophied pigment epithelium with giant multicellular " nest ", adjoining which the rods and cones are much reduced. The ganglion cells are degenerate and there is gliosis of the optic nerve fibre layer. $\times 270$.

terminations of Müller's fibres adjacent to the internal limiting membrane were much increased in number and thickness, and their nuclei stained very deeply.

Case 3 showed certain features not observed in the others. The choroid was not reduced in width, being about $150 \mu$ wide, but the tapetum was narrower than usual and the sides of the cells less regularly arranged (Fig. 2). The centres of many of the multicellular " nests" showed hyaline changes, and there was, in the mid-non-tapetal fundus, about $2 \mathrm{~mm}$. from the papilla, a focus of advanced sclerosis in which an old thrombosed blood vessel was present. Elsewhere the blood vessels of the choroid and retina were normal.

\section{Stage 2}

Clinical Data.-Nine cases were examined at this stage. Vision was obviously abnormal. A common observation with gundogs was that they failed to " mark" a falling bird, and would " over-run" their quarry in retrieving. The dogs could see large objects and recognize their owner at a distance, but had difficulty in seeing near objects, especially if they were small and placed on the ground, i.e. the signs one might expect to observe in a dog with a central scotoma. These defects were not apparently more marked at night. The average pupil size was increased to $8-10 / 14 \mathrm{~mm}$. and varied considerably with the direction of the light beam; the eye preservation reflex was present but sluggish; the pupillary light reactions were sluggish; the lenses and media were clear and the other ocular structures normal. 


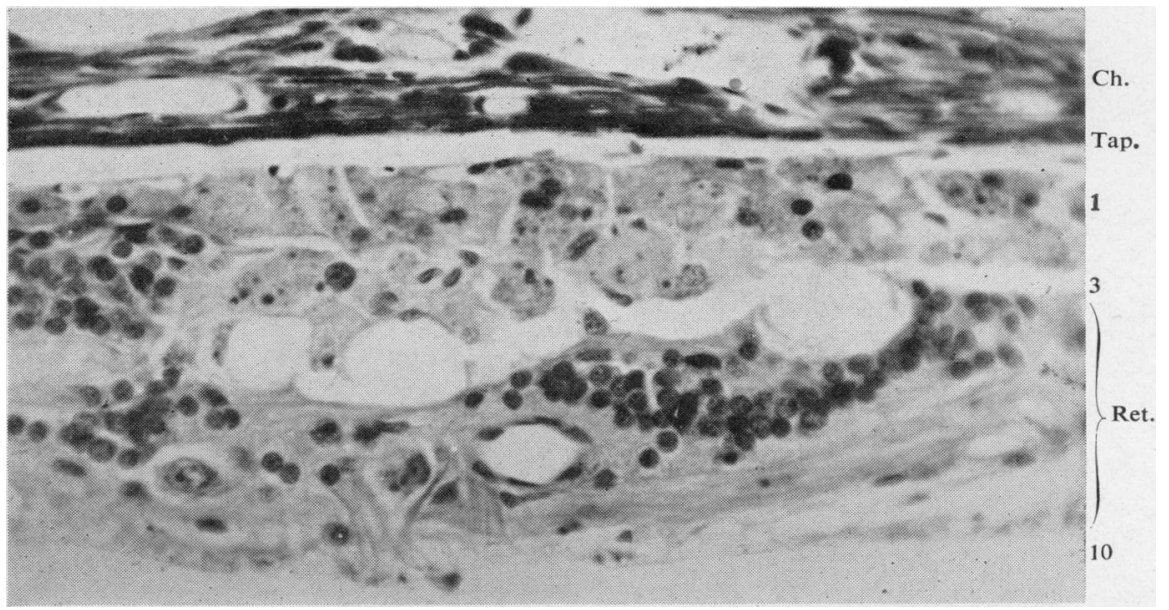

Fig. 4.--Section through retina of 3-yr-old Border Collie dog (Case 4) at Stage $2 a$ of central degeneration; mid-tapetal fundus near papilla. Retina sclerosed. Note giant multicellular " nest" separated in centre from sclerosed retina by cavities situated where rods and cones should be. The choroidal and retinal blood vessels appear normal. Intravital fixation with Kolmer's cold-blooded fluid. Mallory's phosphotungstic acid haematoxylin. $\times 330$.

The tapetal fundus showed the foci of brown granular pigmentation distributed irregularly, and about $0 \cdot 1-0 \cdot 2 \mathrm{~mm}$. in diameter, the texture was slightly crystalline, but the stellulae of Winslow remained. The reflection was increased slightly. The blood vessels of the tapetal fundus were reduced in number; those of the nontapetal fundus were still normal in distribution but had lost their " silver wiring" reflection. The papilla was pale but its primary blood vessels were normal.

Electroretinography.-This was carried out in three cases. The electroretinogram was normal at the beginning of Stage 2 (Case 4), but later the voltage of the negative wave was reduced (Case 10). Case 12 was tested on three occasions in 6 months during which it became completely blind; on the first two occasions a small $b$-wave was present without a negative wave, and on the last occasion the $b$-wave was also missing.

Morbid Anatomy.-Four cases were examined. No significant lesions were noted.

Histology.-The principal features were the continuing degeneration of the central area of the retina until it was completely sclerosed (Fig. 4), while the peripheral fundus remained remarkably normal (Fig. 6), the junction between the two areas being sharply defined (Fig. 5). The retinal blood vessels remained as numerous as in a normal animal.

The central part of the retina, i.e. the whole of the tapetal fundus and the ventral non-tapetal fundus at least half way to the ora serrata, showed loss of the layer organization (Fig. 4) with irregular masses of nuclei, the remnants of the two nuclear layers. Occasional ganglion cells remained. There were no rods or cones. The blood vessels were normal and were quite as numerous as in a normal retina. The pigment epithelium had disappeared in many places, while in others the multi- 


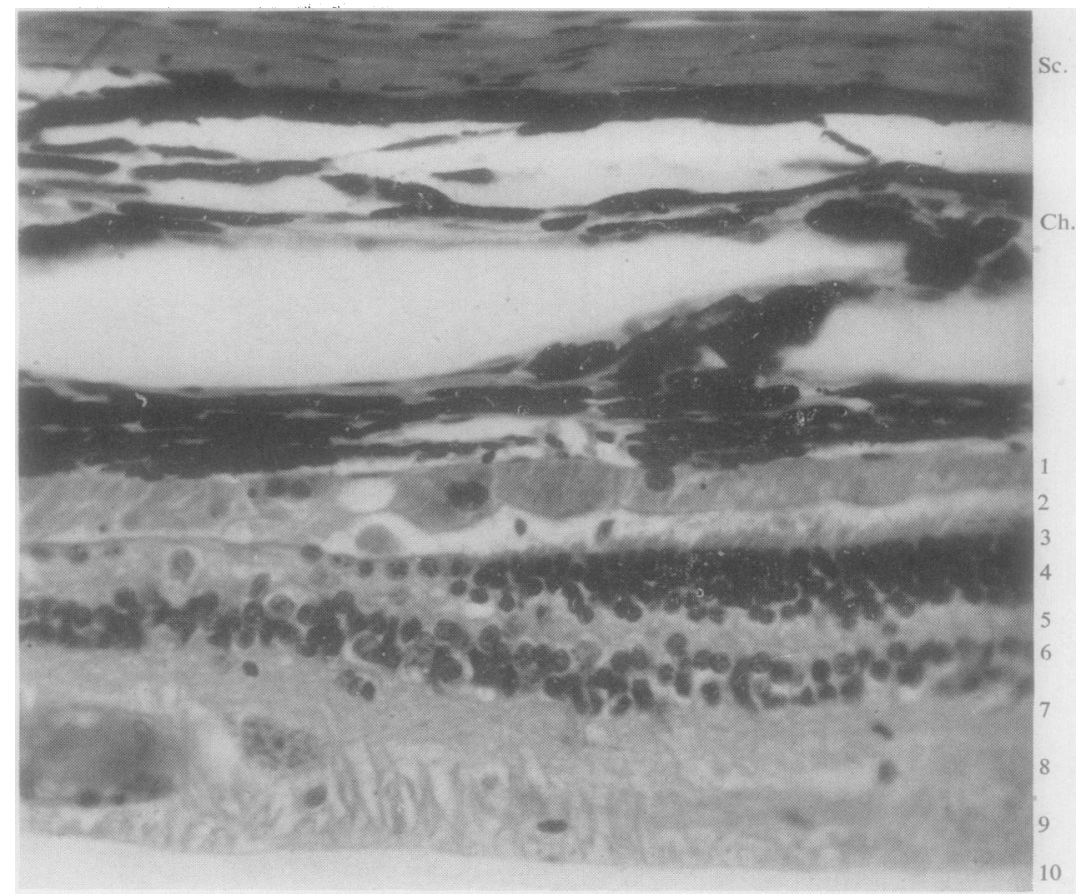

Fig. 5.-Same preparation as Fig 4, junction between sclerosed and normal retina, dorsal junctional zone. Note gradual return of normal retinal layers and pigment epithelium from sclerosed central fundus on left to more normal peripheral fundus on right. With the appearance of less dystrophic pigment epithelium the rods and cones and the outer nuclear layer reappear. The pigment epithelium is still hypertrophied without its normal pigmentation on the right. Ganglion cells are scanty. The thickness of the choroid is reduced. $\times 330$.

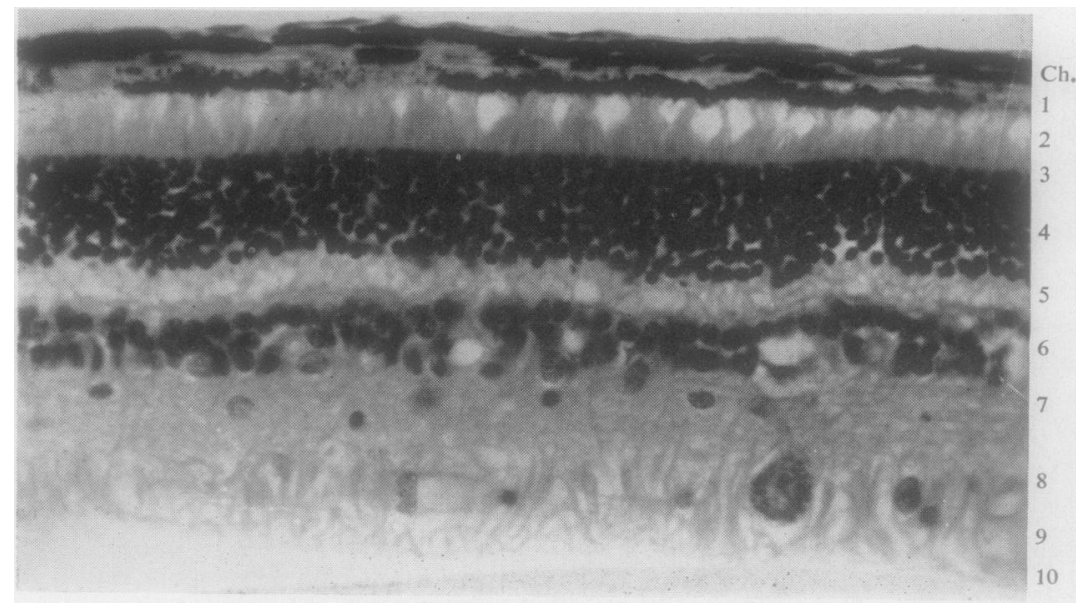

Fig. 6.-Same preparation as Figs 4 and 5; dorsal peripheral non-tapetal fundus. Retina essentially normal. Note normal lanceolate pigment granules in pigment epithelium, and retinal capillaries in inner nuclear and ganglion cell layers. $\times 330$. 
cellular " nests" had enlarged into irregular masses of cells up to $200 \mu$ in diameter, lightly loaded with pigment granules; in yet other portions the pigment epithelial cells were swollen and rounded, $12-15 \mu$ in diameter and with rounded instead of the normal square ends where attached to adjoining pigment cells, and some cells were seen in mitosis. In occasional sites similar cells formed a " cuff " around retinal blood vessels away from the pigment epithelial layer, and more rarely individual pigment cells were seen in the sclerosed retina. The optic papilla was reduced in size and much vacuolated with loss of nerve fibres. The orbital portion of the optic nerve was much less severely affected.

The junction of the central sclerosed part of the retina and the normal peripheral part formed a well-marked ring about $0.5 \mathrm{~mm}$. wide (Fig. 5), in which the normal layers of the retina were present but the pigment epithelium and rods and cones were abnormal. At the central margin the pigment epithelium assumed its normal layer form (Fig. 5), but the cells were still hypertrophic and without normal pigment granules; the rods and cones were absent or reduced to stubby inner limbs only, and the external limiting membrane was no longer firmly adjacent to the pigment epithelium (centre of Fig. 5).

Towards the peripheral margin of the ring the cells of the pigment epithelium were normal in size, and eventually normal lanceolate pigment granules appeared (Fig. 6); coincident with these changes the rods and cones became normal.

The peripheral part of the retina, i.e. the dorsal and ventral peripheral zones and the peripheral part of the mid-tapetal zone, was essentially normal in general morphology (Fig. 6), although there was some gliosis of the nerve fibre layer. The pigment epithelium was normal in size and in the nature and distribution of its pigment granules. Retinal blood vessels were numerous. As these animals had some vision and electroretinograms were recorded from two of them, the functioning of this portion of the retina must have been to a great extent normal.

Blessig-Henlé cavities were present in both eyes of two cases and extended up to $1 \mathrm{~mm}$. from the ora serrata, i.e. twice as far as normally; away from the ora serrata the cavities involved the inner nuclear layer only.

\section{STAGE 3}

Clinical Data.-Four cases were examined. This stage was characterized by the loss of peripheral vision and the development of complete blindness. The pupils were dilated and did not respond to light, the average pupil size was $10 / 15 \mathrm{~mm}$., and the eye preservation reflex was absent. The lenses were clear and no abnormalities of the iris were noted. The tapetal reflection was increased. The fundus was difficult to bring into focus owing to refractive distortion, apparently in the vitreous adjacent to the retina, and the fundus was seen best with a -10 or -15 lens; it showed little change apart from swirling and apparent loss of blood vessels, many of which could be seen buried within the retina. The focal pigment accumulations had disappeared in the advanced cases. The optic papilla was remarkably white, although blood vessels were present.

Electroretinography.-No electroretinogram could be detected in the one animal in which a recording was attempted.

Morbid Anatomy.-No significant lesions were noted in the two cases examined.

Histology.-This stage was similar to the last except that the sclerosis of the central retina was more advanced and the peripheral portion with layer organization 
was still further reduced. The central portion of the retina was reduced to a sclerosed ribbon 10-40 $\mu$ wide. The pigment epithelium was absent except for occasional multicellular " nests", which were disintegrating. Occasional large round cells, some with pigment and some without, occurred throughout the sclerosed retina unrelated to the remaining blood vessels.

The degeneration of the retina had extended further towards the ora serrata, where the extreme peripheral $1-1.5 \mathrm{~mm}$. of retina alone retained the layer organization, this portion being slightly wider ventrally. One case showed marked Blessig-Henlé cavities in one eye, chiefly in the inn er nuclear layer.

(2) Rate of Development of the Disease.-As the earliest clinical signs of the disease can only be detected by ophthalmoscopic examination, and the lesion of the central fundus produces such inconspicuous disturbance of vision, the development of Stage 1 is often overlooked and data relating to it are scanty. Cases 3 and 4, in which an ante-mortem diagnosis was made at this stage, were $1 \frac{1}{2}$ and 3 years old respectively. Nine cases were in the second stage, in which impaired vision is noticeable; this stage either persisted for several years, during which the disease was apparently stationary (Cases $7,10,11$, and 15), or progressed to Stage 3 with complete blindness and the loss of the electroretinogram in about 12 months (Case 12). The presence of some vision after 4 years of known defective vision in Case 10 (which still had an electroretinogram) and after 6 years in Case 15 suggests that the peripheral zone of the retina can be affected extremely slowly by the degenerative process.

(3) Associated Defects. - There were no other ocular abnormalities, except in Case 15, which had small floating opacities in the vitreous humour of the right eye. There have been no other clinical defects.of the nervous system. The general health and development of the dogs were excellent. The gundogs in particular were exceptionally intelligent and several had done well in field trial competitions.

(4) Occurrence of the Disease.-The fifteen cases fall into two groups: Type A, with a marked breed or family incidence, in which the electroretinogram is normal until the disease is far advanced, and Type. B, those without evidence of breed or family incidence, in which changes in the electroretinogram may appear at an earlier stage.

Type A.-There were twelve cases: three Border Collies and nine Retrievers.

The Border Collies (Cases 1, 2, and 4) had been kennelled together at the Research Station with normal dogs used as controls in other studies (Parry, 1953b). They were the survivors of a litter of five, the progeny of a son $\times$ mother test-mating, sent to us at weaning. One pup died of acute leptospirosis at 6 months old and the other died suddenly 3 months after apparent recovery from severe virus hepatitis (Parry, 1950). They had never, as far as is known, been in contact with viruses of the distemper-complex. The mother was blind with a retinal atrophy of uncertain aetiology, which had been first noticed when she was about 4 years old; she was examined at 8 years old when the clinical signs were those of advanced generalized retinal atrophy. No pathological examination was possible. Her son was not examined, but was said to have normal vision.

Of the nine Retrievers, eight were Labradors; six of the nine were males and three females (Table). There was no significant medical history in seven cases; one had convulsions and mental confusion in adolescence which may have been associated 
with distemper-complex infection, and another had had jaundice of unknown aetiology.

Of the eight Labradors, pedigrees were available for Cases 7, 11, 12, 13, and 15, but no details of litter-mates could be obtained. None of these animals was closely related; however, the paternal grandsire of Case 13 was a maternal great-greatgrandsire of Case 15, and a paternal great-great-great-grandsire was common to Cases 7 and 12. Case 11 had no ancestors to the fourth generation in common with the others. A full pedigree was not available for Case 9, but its father had gone blind at 2 years old, and of its three litter-mates, a brother was alive and said to have normal vision, while two sisters had died of para-distemper when 3 years old without abnormal vision being noted. A litter of four pups by Case 9 were alive and the eyes of two examined at 1 year old were normal.

Type $B$ (Cases 3, 8, and 14).-These three cases form a miscellaneous group of one male and two females, of which only Case 3 provided histological data of real value, Case 14 being at a very advanced stage of the disease when examined. Cases 3 and 8 were known to have had para-distemper: in Case 8 the owner associated the onset of defective vision with a severe attack accompanied by other neurological signs which later disappeared. Case 3, a Red Irish Setter, was the progeny of a testmating for the hereditary generalized atrophy (Parry, 1953b), being the only survivor of three litter-mates received at 4 months old while incubating para-distemper; the two litter-mates died from acute para-distemper encephalopathy, but this dog had only a mild febrile illness without clinical signs of involvement of the nervous system.

\section{Discussion}

The data from these fifteen cases of central progressive retinal atrophy, of which ten were examined pathologically, form a well-defined syndrome of bilateral central retinal degeneration with pigment epithelial dystrophy. The syndrome is quite distinct from those reported previously in this series of papers.

The first stage of the disease usually develops during early adult life, although in some no sign of the disease was noted until after middle age. The onset is indefinite on account of the slow development of the central scotoma. The earliest stage of the disease will often go unrecognized unless routine ophthalmoscopic examinations are being made. Peripheral vision, both by day and night, remains normal until the third stage of the disease, and until then the peripheral portion of the retina is probably fully functional since the electroretinogram is normal. The degeneration affects the retina of the central fundus, including the whole of the tapetal fundus as far as the outer part of the mid-ventral zone, i.e. about half-way to the ora serrata. The area of affected fundus is rather more extensive in the dorsal than the ventral quadrants.

The pigment epithelium is the first layer of the neuro-epithelium to show any abnormality. The typical foci of pigment epithelial cells can only be seen with the ophthalmoscope over the tapetal fundus, but histological preparations show that the foci also occur over the non-tapetal fundus, where their presence is masked in life by the underlying choroidal pigment. 
Only when the pigment epithelium is definitely dystrophic with hypertrophic cells and multicellular " nests" do the rods and cones begin to show degenerative changes. These changes are particularly marked near the multicellular " nests", but there is a general loss of first-order neurones over the whole of the central fundus, until the rods and cones disappear and the outer nuclear layer is reduced to a single layer of cone nuclei. The inner nuclear layer remains normal until a later stage and it forms the bulk of the residual nuclei which finally fuse to form a single irregular nuclear layer. At an early stage of the degeneration, before there is any appreciable loss of first-order neurones, the optic nerve fibres of the papilla and immediate peripapillary zone show degeneration and vacuolation, which is no doubt responsible for the abnormal pallor of the papilla noted in life. About the same time the glial network immediately adjacent to the internal limiting membrane becomes prominent through the proliferation of Müller's fibres, the nuclei of which stain abnormally prominently. There is a modest loss of large ganglion cells, particularly near the papilla, but some large ganglion cells remain even when the retina is sclerosed.

The dystrophy of the pigment epithelium shows three features of special interest: general hypertrophy with abnormal pigment formation, individual giant cells, and multicellular " nests". These are probably three phases of the same reaction to an abnormal environment, for the hypertrophic cells have been observed in metaphase, and from such dividing cells the multicellular " nests" could readily arise. These features have not been observed in normal eyes, but a modest generalized regular hypertrophy and a massive irregular focal hypertrophy occur in distemper retinopathy (Parry, 1954). However, in distemper retinopathies, the pigment cells maintain a regular layer arrangement, while in central atrophy the cells tend to have convex ends, become rounded, and form small groups, and some of them may break away from the layer as loose cells. The multicellular " nests " are presumably a more advanced stage of cell proliferation; they do not occur in close relation to blood vessels, although occasionally a focus was seen immediately beneath a large retinal artery.

Proliferation of the pigment epithelium has been reported in amphibia following experimental removal of the retina (Stone, 1950), and it occurs in some human cases of nephritic retinitis (Koyanagi, 1934; Duke-Elder, 1940a) and pseudo-retinitis pigmentosa (Cogan, 1950). Koyanagi shows a multicellular " nest" in Fig. 12 of his paper, which is very similar to those seen in these dogs. The masses of heavily pigmented cells illustrated by Cogan in Figs 24-29 of his paper are less similar, but it is of interest that there is evidence of an old inflammatory reaction with choroidal damage in each of his three cases. In these instances of dystrophy of the pigment epithelium in man there are grounds for believing that the circulation through the adjoining choroid has been inadequate, and it seems probable that these types of pigment dystrophy may be related to a pre-existing insufficiency of the choroid and its circulation due to inflammation or other causes. On 
the other hand, Keyes and Goldblatt (1938) observed atrophy of the choroid in dogs with experimental malignant hypertension, in which severe damage to the walls of the blood vessels of the uveal and retinal systems occurred; their report contains no special mention of pigment epithelial dystrophy, although they observed iron-containing pigment in old retinal scars following extensive haemorrhages into the retina.

The occurrence of such extensive pigment dystrophy invites consideration of any possible relationship between the dog syndrome and human diseases of the retinitis pigmentosa group. Sorsby (1940), discussing abiotrophies of the retina and choroid, mentions two types of central retinal abiotrophy: macular dystrophies and angeoid streaks. Although there is a not dissimilar defect of vision in the former, neither seems at all similar to the dog disease, since the dog does not have a macula and the atrophy is not confined to the area centralis, nor have fundus changes resembling those seen in man been observed in the dog. Similarly, in the classification of the primary chorioretinal aberrations with night blindness occurring in man (Leinfelder, 1950), there is no category into which the canine central atrophy appears to fit.

However, the syndrome described by Stock $(1908,1936)$ provides a closer resemblance. He reported on three human cases of retinal degeneration with pigment dystrophy, first affecting the central fundus and then spreading slowly outwards towards the periphery. Night blindness did not occur until day vision was nearly lost, but other serious defects of the central nervous system indicative of widespread damage to the brain developed, a complication absent in the dog. The aetiology of Stock's syndrome is uncertain, and any close comparison with the dog disease must remain speculative in the absence of detailed histological data.

The first cases of the dog disease suggested that we might be dealing with a form of central angiospastic retinopathy (Gifford and Marquardt, 1939; Duke-Elder, 1940b), or of the central serosal retinitis common in Japan (Asayama, 1892; Masuda, 1918; Oguchi, 1922; Kitahara, 1936), which Ko (1935) has suggested might be due to some pathological photosensitization of the central retina. However, in these syndromes, oedema of the macula occurs and recovery without permanent impairment of vision is usial, although recurrences often occur in the angiospastic retinopathy; these features have not been observed in the dog syndrome. We have also failed to observe signs of angiospasm in life, nor have microscopic abnormalities of the remaining choroidal and retinal blood vessels been seen constantly. Similarly, any close relationship to the senile macular chorio-retinal degeneration of Haab (Duke-Elder, 1940c) seems unlikely, as the chorio-capillaris is spared in the dog disease and irregular sclerotic changes in the choroidal blood vessels have not been observed.

In short, we have failed to find a description of a human syndrome which resembles closely this central retinal atrophy of the dog, although it has similarities to some forms of retinitis pigmentosa. 
Before discussing the aetiology of the dog syndrome, one should consider possible reasons for the central distribution of the degeneration and its sequence within the retina, which are, as far as we know at present, quite characteristic. The main features could be explained by postulating an inadequate circulation through the posterior portion of the choroid, thereby affecting the circulation to the chorio-capillaris of the central fundus and the outer layers of the overlying neuro-epithelium, whilst leaving intact the inner layers of the retina supplied by the central retinal artery. Such a disturbance would also explain the early degeneration of the papilla and peripapillary optic nerve fibres, a region supplied by the secondary cilio-retinal arteries arising from the choroidal circulation near the optic nerve head and probably receiving very little blood from the central retinal system.

There is some support for such an hypothesis from human and experimental ophthalmology. A similar distribution and type of degeneration has been reported in one human eye after the severing of the central retinal and posterior ciliary arteries (Komoto, 1915). In this eye 12 days after operation the whole of the central, i.e. posterior, fundus was sclerosed, while the extreme peripheral retina was spared and was essentially normal, although there may have been some loss of third-order neurones. The experimental severing of the posterior ciliary arteries of rabbits (Nicholls, 1938) produced a sequence of degeneration similar to that seen in the dog disease, but the degeneration was confined principally to the equator, although there was oedema of the central fundus. Nicholls found that the extent of the degeneration varied very much with the extent of the surgical interference, so that about twothirds of the posterior ciliary arteries had to be severed to get an appreciable lesion, and that in producing this there was inevitably considerable damage to the ciliary nerves. It may well be that a more complete interruption of the blood supply through all the short posterior ciliary arteries would have produced a severe degeneration of the whole of the central fundus. The peripheral fundus in his rabbits was spared, as the anterior ciliary circulation was unaffected.

Sparing of the peripheral retina is also seen after occlusion of the central retinal artery in man (Hancock, 1908; Coverdale, 1929; Duke-Elder, 1940d), which suggests that the inner layers of the peripheral zone of the retina receive their blood supply from the choroidal rather than from the retinal system.

In central retinal atrophy in the dog, all the retinal layers of the posterior part of the eyeball are degenerate by the end of the first stage, i.e. the inner layers supplied by the central retinal system are not spared, although they are affected less early outside the peripapillary fundus. The choroidal circulation in this posterior region of the eyeball is probably supplied by the short posterior ciliary arteries (Nicolas, 1925a; Sisson and Grossman, 1938), although it is uncertain whether the branches of the short posterior ciliary arteries anastomose with those of the anterior ciliary arteries in the dog as they do in man (Nicholls, 1938), or whether the terminal branches of both anterior and short posterior ciliary arteries are end-arteries at the equator 
as in the rabbit (Nicholls, 1938). The short posterior ciliary arteries probably arise direct from the ciliary artery (Nicolas, 1925a), while the anterior ciliaries arise from the artery to the extrinsic ocular muscles (Nicolas, 1925b), which is a branch of the external ophthalmic artery arising independently of the ciliary artery some distance central to the junction of the latter with the internal ophthalmic artery from the circle of Willis (Daniel and others, 1953).

The involvement of the inner layers of the retina does not necessarily imply interference with the blood supply of the central retinal system, as a similar degeneration follows degeneration of the first-order neurones, e.g. as in hereditary generalized atrophy. However, if the central retinal artery does arise from the short posterior ciliaries close to the eyeball (Wolff and Davies, 1931), and not from the external ophthalmic artery (Nicolas, 1925a; Sisson and Grossman, 1938), then disturbances in the posterior choroidal circulation may occur also in the central retinal system.

Thus it is possible to explain the principal features of the central atrophy on the hypothesis of an inadequate blood supply through the choroidal circulation from the short posterior ciliary arteries, followed by slow failure of the supply to the anterior parts of the choroid from the anterior ciliary arteries. A cardinal difficulty in accepting this explanation is that we have no satisfactory morphological evidence to support it, for, although the choroid may have been thinned slightly, there were no constant changes in the blood vessel walls and no signs of choroiditis, while the retinal blood vessels appeared to be, if anything, more numerous than usual. It is possible that any disturbance of the blood supply, whether due to anatomical or to physiological causes, may have been located in the orbit central to the eyeball, and may, therefore, have escaped attention. The use of our material for general cytological study precluded adequate study of these circulatory problems, the significance of which only came to light as a result of the cytological study.

These considerations, taken in conjunction with the data on the occurrence of the atrophy, suggest that the Type A cases are most probably due to a spontaneous abiotrophy (Treacher Collins, 1919). The breed and family incidence point to a genetic basis, although the evidence is as yet insufficient to establish the hereditary origin of the syndrome, let alone indicate its mode of inheritance beyond showing that it cannot be due to a simple Mendelian dominant gene or be completely sex-linked. The data from the Border Collie litter would fit inheritance by a simple Mendelian recessive gene. With regard to the three cases of Type B, the data is insufficient to exclude environmental factors such as distemper-complex infection, and, until more information is available, it seems wiser not to include them with the Retriever and Border Collie cases in the " possibly hereditary" category.

\section{Summary}

(1) A series of fifteen cases of progressive degeneration of the central portions of the retina with pigment epithelial dystrophy is described; ten cases were examined pathologically. 
(2) Affected dogs develop a central scotoma by early or middle adult life while retaining normal peripheral vision by day and night, often for years.

(3) The retinal degeneration begins overthe tapetal and dorsal non-tapetal fundus; hypertrophy of the pigment epithelium is followed by atrophy of the rods and cones and the outer nuclear layer, and sclerosis of the central retina.

(4) Multicellular " nests" of pigment epithelial cells occur; they may be sien in the tapetal fundus with the ophthalmoscope.

(5) The electroretinogram remains normal until the later stages of the disease, when first the negative wave and then the $b$-wave are lost.

(6) Two types of the syndrome are recognized: Type A, familial, in Retrievers and Border Collies, possibly due to an inherited abiotrophy; Type B, sporadic, of uncertain aetiology.

(7) The pathogenesis of the degeneration and the possible role of disturbances of the blood supply in its causation are discussed. The relationship of the disease to human retinitis pigmentosa is considered.

It is a pleasure to acknowledge the help of Dr. Katharine Tansley and of Dr. L. C. Thomson with the histology and electroretinography, and Mr. C. F. Hart's skill in preparing the sections.

\section{REFERENCES}

AsAyAma, I. (1892). Nippon-gankagakkai Zasshi (Quoted by Oguchi, 1922).

Cogan, D. G. (1950). Trans. Amer. Acad. Ophthal. Otolaryng., 54, 629.

Collins, E. Treacher (1919). Trans. ophthal. Soc. U.K., 39, 165.

Coverdale, H. V. (1929). British Journal of Ophthalmology, 13, 529.

Daniel, P. M., Dawes, J. D. K., and Prichard, M. M. L. (1953). Philos. Trans. roy. Soc., 237, 173.

DUKE-ELDER, S. (1940a). "Text-book of Ophthalmology", vol. 3, p. 2720. Kimpton, London. (1940b). Ibid., p. 2592. (1940c). Ibid., p. 2372 (1940d). Ibid., p. 2563.

Gifford, S. R., and MARQUARDT, G. (1939). Arch. Ophthal. (Chicago), 21, 211.

HANCOCK, W. I. (1908). Roy. Lond. ophthal. Hosp. Rep., 16, 428.

KeYes, J. E. L., and GoldblatT, H. (1938). Arch. Ophthal. (Chicago), 20, 812.

Krtahara, S. (1936). Klin. Mbl. Augenheilk., 97, 345.

Ko, H. -U. (1935). Acta Soc. ophthal. jap., 39, 8P.

Komoto, G. (1915). Trans. ophthal. Soc. U.K., 35, 295.

Koyanagi, Y. (1934). v. Graefes Arch. Ophthal., $132,353$.

LeINFelder, P. J. (1950). Trans. Amer. Acad. Ophthal. Otolaryng., 54, 607.

MASUDA. T. (1918). Nippon-gankagakkai Zasshi. (Quoted by Oguchi, 1922).

Nichols,, J. V. V. (1938). British Journal of Ophthalmology, 22, 672.

Nicolas, E. (1925a). "Veterinary and Comparative Ophthalmology", trans. and enlarged H. Gray, p. 213. Brown, London. (1925b). Ibid., p. 214.

(1925c). Ibid., p. 270.

OGUCHI, C. (1922). v. Graefes Arch. Ophthal., 110, 25.

PARRY, H. B. (1953a). British Journal of Ophthalmology, 37, 385.

(1953b). Ibid., 37, 487. (1953c): Ibid., 37, 670. (1954). Ibid., 38, 295.

Trensey, K., AND Thomson, L. C. (1953). J. Physiol. (Lond.), 120, 28.

Sisson, S., and Grossman, J. D. (1938). "The Anatomy of the Domestic Animals", 3rd ed. Saunders, Philadelphia.

Sorsby, A. (1940). In " Modern Trends in Ophthalmology ", ed. F. Ridley and A. Sorsby, pp. 459 et seq. Butterworth, London.

Stock, W. (1908). Klin. Mbl. Augenheilk., 46, 225. (1936). Ber. dtsch. ophthal. Ges., 51, 106.

Stone, L. S. (1950). Anat. Rec., 106, 89.

WolfF, E., and DAVIES, F. (1931). British Journal of Ophthalmology, 15, 609. 